\title{
DISCOURSE-CONDITIONED LEXICAL AND SEMANTIC TRANSFORMATION OF WORDS IN THE AMERICAN AND BRITISH POLITICAL DISCOURSE
}

\author{
Tatyana M. Golubeva \\ Kozma Minin Nizhny Novgorod State Pedagogical University (Minin University), \\ Nizhniy Novgorod, Russian Federation
}

\begin{abstract}
The research is conducted within the framework of critical discourse analysis and aims to identify and describe the cases of transformation of connotation-free lexis into the words having distinct positive or negative evaluative connotations under the influence of dominant ideology and conventional social representations. The corpus of data under investigation is made up of elements of British and American political discourse: editorials of the broadcasting corporation "Voice of America", speeches of British and American politicians, commentary of participants of political Internet-forums. In American political rhetoric the neutral word democracy acquires an axiological character. As a result, in some cases the substantivized relative adjective democratic develops a qualitative meaning and serves to express a positive evaluative characteristic. The lexemes fascism, communism, socialism, etc. referring to alien, i.e. anti-American, ideologies participate in the making of invective labels and nicknames which target is to discredit famous politicians. In the speeches of British government officials the toponym European becomes axiologically relevant and actualizes such commonly acknowledged values as freedom, democracy, security and prosperity. Due to metonymic transfer the anthroponym Assad acquires negative evaluative connotations and becomes a substitute of the concept Assad's regime, thus conditioning the formation of a hostile and suspicious attitude to the actions of Syrian president Bashar al-Assad.
\end{abstract}

Key words: connotation-free concept, connotation, value, invective label, metonymy, political discourse.

\section{ДИСКУРСИВНО ДЕТЕРМИНИРОВАННАЯ ЛЕКСИКО-СЕМАНТИЧЕСКАЯ ТРАНСФОРМАЦИЯ СЛОВ В АМЕРИКАНСКОМ И БРИТАНСКОМ ПОЛИТИЧЕСКОМ ДИСКУРСЕ}

\author{
Татьяна Михайловна Голубева \\ Нижегородский государственный педагогический университет имени К. Минина, \\ г. Нижний Новгород, Российская Федерация
}

\begin{abstract}
Аннотация. Данное исследование выполнено в рамках критического дискурс-анализа и имеет целью выявить и описать случаи трансформации оценочно нейтральных лексем в слова с выраженными положительными или отрицательными оценочными коннотациями под воздействием доминирующей идеологии и общепринятых социальных представлений. Материалом для изучения послужили фрагменты англоязычно글 го политического дискурса: редакторские статьи телерадиовещательной корпорации «Голос Америки», выخे ступления британских и американских политиков, комментарии участников политических интернет-форум мов. Показано, что в американской политической риторике оценочно нейтральное слово democracy приобретает аксиологическую направленность, благодаря чему в некоторых случаях отсубстантивное относительное прилагательное democratic развивает качественное значение и используется для выражения положительного оценочного признака. Лексемы, эксплицирующие чуждые американскому обществу идеологии, ริ участвуют в создании инвективных ярлыков и прозвищ, применяемых с целью дискредитации известных () политических деятелей. В выступлениях членов британского правительства топоним European становится
\end{abstract}


аксиологически значимым и дискурсивно соотносится говорящими с такими общепризнанными ценностями, как свобода, демократия, безопасность и процветание. Вследствие метонимического переноса антропоним Assad приобретает отрицательные оценочные коннотации и становится референтом понятия «режим Ассада», обусловливая формирование негативного отношения к деятельности сирийского президента.

Ключевые слова: оценочно нейтральное понятие, коннотация, ценность, ярлык-инвектива, метонимия, политический дискурс.

\section{1}

Взаимодействие языка и общества является предметом многочисленных социолингвистических исследований, проводимых с опорой на концептуально-методологическую базу критического дискурс-анализа. Исходя из трактовки языка как «средства доминирования и социальной силы» [Habermas, 1968], представители данного научного направления анализируют как завуалированные, так и прозрачные структурные взаимоотношения дискриминации, власти и контроля, манифестированные в языке. К задачам критического дискурс-анализа относятся идентификация, описание и интерпретация фактов проявления власти и дискриминации в дискурсивной практике и за ее пределами посредством лингвистического анализа. Британский лингвист Н. Фэрклаф проводит исследование языка средств массовой информации как сферы реализации власти и конфликта [Fairclough, 2001]. В работах голландского ученого Т. ван Дейка разрабатывается теоретическая модель понимания когнитивных механизмов, участвующих в актуализации расистской идеологии посредством дискурса [Dijk, 1998]. Американские социолингвисты К. Уэст и Д. Зиммерман освещают вопрос гендерного доминирования в коммуникативных практиках [West, Zimmerman, 1987]. Теоретик французской школы критического дискурс-анализа М. Пешо описывает идеологичность дискурсивных формаций, акцентируя внимание на анализе идеологических измерений использования языка и материализации идеологии в языке [Рecheux, 1982]. Австрийские исследователи Г. Вайс и Р. Водак проводят в своих работах деконструкцию общества для того, чтобы установить, как социальное неравенство выражается и узаконивается посредством языка [Weiss, Wodak, 2002]. Основополагающей для критического дискурс-анализа является мысль о том, что дискурс репрезентирует весь процесс социальной интеракции, а формальные элементы текста представляют собой «следы» в процессе его создания и «ключи» в процессе его интерпретации [Fairclough, 2003, с. 24]. Наиболее отчетливо отношения между языком и властью эксплицируются в политическом дискурсе, что делает данный вид речевой практики предметом особого внимания и интереса ученых.

Исследование, проводимое в данной статье, выполнено в обозначенном теоретическом формате и имеет целью описать конкретные случаи дискурсивно обусловленной лексико-семантической трансформации слов под воздействием доминирующей идеологии и культуры. В частности, в статье выявлены и охарактеризованы особенности использования лексем, обозначающих оценочно нейтральные понятия, в качестве единиц, обладающих выраженными положительными или отрицательными коннотациями. Материалом для исследования послужили фрагменты англоязычного политического дискурса: выступления британских и американских политиков, тексты политических статей и комментарии участников интернет-форумов.

2

Анализ редакторских статей телерадиовещательной корпорации правительства США «Голос Америки», представленных под рубрикой «Демократия и управление», свидетельствует о том, что нейтральное понятие «демократия» имеет в данном виде дискурса дополнительные, оценочные смыслы. О способности данного понятия развивать новые значения упоминают многие исследователи. Так, В.И. Карасик относит его к категории эпиномных концептов или эпиномов - лабильных смысловых образований с редуцированным, ситуативно обусловленным предметным и гипертрофированным эмоционально-оценочным содержанием [Карасик, 2010]. Изучая в 
своих работах манипулятивный аспект необоснованного использования комплексных понятий, Н. Эллот отмечает, что «слово демократия, которое, как правило, обозначает политическую систему, где граждане страны принимают участие в принятии решений, иногда может обозначать политическую систему со свободой инвестиций или что-либо подобное. Кроме того, данное понятие используется иногда лишь для того, чтобы вызвать позитивные суждения, и может быть дополнено каким угодно смыслом» [Allott, 2005, p. 152] (здесь и далее перевод с английского наш. $T$. Г.). Для определения значения существительного democracy рассмотрим его словарные дефиниции:

democracy n. 1. a system of government by the whole population or all the eligible members of a state, typically through elected representatives; 1.1 a state governed under a system of democracy; 1.2 control of an organization or group by the majority of its member; 1.3 the practice or principles of social equality (OD).

Согласно данным словаря, слово democracy является оценочно нейтральным и обозначает систему государственного устройства, для которой характерно народовластие, подконтрольность государственного управления избирателям и социальное равенство. Однако, как показывает анализ, в текстах редакторских статей ТРК «Голос Америки» денотативное значение лексемы democracy размывается и на передний план выступают коннотации, имеющие выраженные ценностные характеристики, то есть понятие, эксплицированное данной лексемой, приобретает аксиологическую направленность. Трактуя аксиологичность как функциональную семантико-стилистическую категорию, как способность понятия транслировать ценности [Марьянчик, 2006], можно утверждать, что аксиологические понятия сосредоточивают в себе представления о морально-этических, социально-культурных и другого рода ценностях.

Исследование показало, что в американском политическом дискурсе понятие «демократия» актуализирует такие значимые общественные ценности, как «мир» и «процветание». Например, в статье, посвященной теме визита Госсекретаря США Дж. Керри в Кыргызстан, приводится высказывание этого по- литика о том, что демократия как тип государственного устройства является гарантом «процветания и мира»: Aside from the economic benefits, a critically important function of education, said Secretary of State Kerry, is that it provides a fundamental foundation for democracy. "And democracy," he said, "is in turn the foundation of a lasting ability to have prosperity and peace" (V). $\mathrm{B}$ другой редакторской статье, осуждающей столкновения между представителями религиозных сект в Центрально-Африканской Республике, высказывается мнение о том, что только правительство, избранное демократическим путем, может обеспечить «устойчивый мир и экономическое благополучие»: It is critical that elections take place to allow a democratically-elected government to lead the citizens of the Central African Republic to lasting peace and recovery (VII). В статье, описывающей официальный визит Дж. Керри в Тунис, словосочетания emerging democracy «развивающаяся демократия» и growing prosperity «растущее процветание» образуют фразовое единство, элементы которого связаны соединительным союзом and «и»: In order to protect Tunisia's emerging democracy and growing prosperity, it is essential to enhance security cooperation (VI). Благодаря наличию синтаксически обусловленной смысловой связи между словами democracy и prosperity актуализируется представление о том, что демократические преобразования являются залогом экономического процветания общества.

Специфика аксиологической наполненности понятия «демократия» в текстах редакторских статей раскрывается не только благодаря сопоставлению его с понятиями, актуализирующими те или иные ценности, но и за счет противопоставления антиценностям. Так, в речи заместителя госсекретаря А. Блинкена антиподами демократии, которая, по его мнению, подразумевает «мирную реализацию гражданами своих прав, амбиций и потребностей», выступают глобальные общественные угрозы - экстремизм и радикализм: "Democracy is the frontline of our defense," said Deputy Secretary Blinken. "It serves as the bulwark against extremism and radicalization precisely because it gives all 
people the opportunity to express their rights, pursue their ambitions, and redress their grievances peacefully" (III). Однако анализ данных тезауруса не выявил наличия у существительного democracy упомянутых антонимов: в качестве противоположных по смыслу слов в словаре приводятся термины autocracy, dictatorship, dominance, inequality и т. п. (PT). Использование лексем extremism «экстремизм» и radicalization «радикализм», очевидно, дискурсивно обусловлено. Благодаря этому противопоставлению понятие «демократия» «транслирует» такие значимые и признанные общественные ценности, как «умеренность», «толерантность» и «миролюбие». Согласно другому утверждению А. Блинкена, деятельность авторитарных правителей и экстремистов носит деструктивный характер, поскольку они проводят «политику разделения» и создают «идеологии ненависти». Следуя логике высказывания американского политика, можно сделать вывод о том, что демократии как антиподу авторитаризма и экстремизма должны быть присущи иные, конструктивные признаки, а именно: «всеобщее единение», «солидарность», «согласие», «гуманность» и «нравственная культура»: As we take action in defense of our values and those who share them, said Deputy Secretary Blinken, authoritarians and extremists will find that their politics of division and ideologies of hate will have precipitated exactly what they hoped to destroy: a world of civility and a resurgence of faith in the democratic ideal (III).

В ходе исследования было также установлено, что выраженный коннотативный компонент значения слова democracy в некоторых случаях обусловливает окачествление отсубстантивного относительного прилагательного democratic «демократический». Оно приобретает качественное значение, будучи членом цепочки однородных определений, выраженных, как правило, качественными прилагательными положительной оценки, в частности peaceful «мирный» и prosperous «процветающий». При этом democratic обозначает некий отвлеченный положительный признак и служит не для характеристики типа общественных отношений, а для усиления общего эмоционально-оценочного заряда высказывания. Примером тому может служить словосочетание a strong, stable, democratic and prosperous future, в котором прилагательное democratic подвергается десемантизации и переходит в разряд оценочной лексики: The United States remains committed to working with the government and people of Azerbaijan in their effort to ensure a strong, stable, democratic and prosperous future (VIII). «Истирание» денотативного значения и выдвижение положительных оценочных коннотаций в позицию смыслового ядра у слова democratic наблюдается и в следующем высказывании: Regular, peaceful, democratic leadership transitions provide a dynamic and healthy mechanism for citizens to hold political leaders accountable for their governance and foster long-term stability (IV). В контексте A number of obstacles are built into the system, preventing a truly democratic process (I) наличие интенсификатора truly «по-настоящему» перед прилагательным democratic «демократический» в словосочетании a truly democratic process «по-настоящему демократический процесс» также свидетельствует о появлении у рассматриваемого прилагательного градуированного качественного признака. Американский представитель в Организации по безопасности и сотрудничеству в Европе Дэйниэл Баер использует выражение $a$ unified, democratic, prosperous, European Ukraine «объединенная, демократическая, процветающая, европейская Украина», в котором понятие «демократический» реализуется как аксиологическое, поскольку Украина де-юре уже является демократическим государством: It is the voices of people like Oleksandra... who demand fairness and respect for human rights, who are committed to a unified, democratic, prosperous, European Ukraine (II). В этом выказывании раскрывается еще одно аксиологическое понятие - «европейский»: в данном случае речь идет не о местонахождении Украины на карте мира, а об идеологической ориентации этой страны. В Оксфордском словаре английского языка приводятся следующие дефиниции слова European «европейский»:

European adj. 1. of or relating to Europe or its inhabitants; 1.1 of or relating to the European Union; n. 1. a native or inhabitant of Europe; 1.1 a national of a state belonging to the European 
Union; 1.2 a person who is committed to the European Union; 1.3 a person of European parentage (OD).

Таким образом, согласно данным словаря, лексема European имеет топонимическую отнесенность, если речь идет о географическом объекте - европейском континенте, и политико-экономическую отнесенность, если имеется в виду территориально-общественная формация Европейский союз. Однако анализ американского и британского политического дискурса показывает, что понятие «европейский» имеет выраженную аксиологическую направленность. Рассмотрим подробнее, какие ценности с ним соотносятся. В своем выступлении в Таллине в апреле 2014 г. министр по европейским делам МИД Великобритании Д. Лидингтон призывает Евросоюз действовать сообща, чтобы противостоять российской «агрессии» на Украине и защитить свои, европейские ценности - «безопасность, уверенность в завтрашнем дне и процветание»: Whether on energy security or on our general competitiveness, the situation in Ukraine has underlined the need for action to preserve and strengthen our values of safety, security and prosperity (XV). Выступая с речью в Берлине в июне 2014 г., Д. Лидингтон позиционирует Европу как территорию «демократии и правопорядка», одновременно обосновывая экспансионистскую политику Евросоюза стремлением сделать эти ценности достоянием соседних государств: And we have worked closely with Germany and others to expand the borders of the EU to spread democracy, human rights and the rule of law in those parts of our continent where those values were crushed for most of the twentieth century (XII). Следуя логике высказываний Д. Лидингтона, страна, вступающая в Евросоюз, автоматически приобретает статус правового и демократического государства. Эта идея реализуется, в частности, в его заявлении о том, что благодаря Евромайдану (вооруженному захвату власти в Киеве сторонниками евроинтеграции в феврале 2014 г.) у Украины появилась перспектива стать современным и процветающим европейским государством: The ground is now set, a year on from EuroMaidan, for Ukraine to transform itself into a modern and prosperous European state (XV).
Комментируя вооруженное нападение мусульман-террористов на офис редакции французского сатирического журнала в янваpe 2015 г., главный секретарь казначейства Великобритании Д. Элигзэндер говорит о новой идентичности - «европейский человек», которая дискурсивно отождествляется с такими ценностями, как «свобода», «благопристойность» и «свобода слова». Сам себя он характеризует посредством фразы $a$ passionate and committed European «ярый и неисправимый европеец», в которой понятие «европейский» аксиологично: I would like to start by saying that I am a Highlander. I am also a Scot. I am British. And I am also a passionate and committed European. The horrifying recent events in Paris have of course overshadowed everything else during the past 2 weeks. Of course, it was an attack on the values we all share in the Western world. Values of liberty, of decency, and of free speech (X). Таким образом, британский политик идеологически консолидирует разнородное европейское сообщество и одновременно воспроизводит стереотипы о демократичности, справедливости и нравственности европейского мироустройства. В речи, посвященной теме введения политических и экономических санкций в отношении РФ, премьер-министр Великобритании Дэвид Кэмерон использует выражение a free, European future «свободное, европейское будущее», в котором прилагательное European не имеет четко определенного значения, а лишь выражает какой-то положительный оценочный признак и в этом отношении может рассматриваться как синоним слова good «хороший»: So we must stand up to aggression, uphold international law and support people who want a free, European future (XI).

Как показывает анализ, в американском и британском политическом дискурсе «свои» общественные идеологии и политические системы актуализируют значимые социальные и моральные ценности, в то время как «чужим» политическим системам и идеологиям приписывается антиценностный характер. Так, анализ политических статей и комментариев 
участников интернет-форумов, представленных в американском медиа-пространстве, свидетельствует о том, что некоторые негативно-оценочные ярлыки или прозвища, которые получают известные американские политики, актуализируют такие идеологические понятия, как «фашизм», «нацизм», «социализм», «коммунизм» и «марксизм». Первоначальная категоризация данных понятий как враждебных, антиамериканских идеологий обусловила формирование определенных социальных представлений, в рамках которых они ассоциируются со злом, угрозой, опасностью. Поскольку для носителей американской культуры данные понятия актуализируют антиценности, то прозвища, созданные на их основе, очевидно, имеют целью дискредитировать человека, его действия или политическую позицию. Это, в свою очередь, свидетельствует о наличии у таких идеологических ярлыков инвективной направленности, то есть в дискурсе они выполняют функцию лексических инвектив. Отметим, что инвектива, актуализируемая на лексическом, фразеологическом, текстовом уровне, является выражением вербальной агрессии, поскольку она содержит намерение оскорбить, опорочить, унизить референта речевого высказывания.

Степень инвективной насыщенности идеологических ярлыков концептуально детерминирована. Наиболее интенсивно инвективная составляющая проявляется в ярлыках, апеллирующих к понятиям «фашизм» и «нацизм»: Fascist Hillary Clinton and the Democratic Party's paternalistic form of fascism is as dangerous to our civil rights, the rule of law, the democratic political process, and the separation of church and state as the fascist Bush regime and the Republican Party's form of military / police state fascism (XVII); The Bushes and Clintons and puppet Obama are birds of a feather, all Nazis... The transcript provides evidence that Clinton hurt Gore in many ways maybe actually wanting the Nazi Bush II to continue the Nazi destruction of America (XVII).

Данные примеры показывают, что «фашистская / нацистская〉 ориентация может быть присвоена любому политику независимо от его партийной принадлежности. Ярлыки fascist / Nazi начинают выполнять функции бранных слов, приближаясь по своему значению к литературным ругательствам. В некоторых случаях апелляция к идеологическим понятиям «фашизм» и «нацизм» при характеристике политических убеждений человека позволяет говорящему подвергнуть сомнению их приемлемость и адекватность. Например, ярлыки демократа Хиллари Клинтон femi-Nazi и liberal fascist дают понять, что ее приверженность идеям либерализма и равноправия полов носит радикальный характер и поэтому может представлять угрозу для общества.

Лексемы socialism, communism, Marxism в той или иной степени сохраняют свое предметное значение, ведь именно с опорой на обобщенное знание о сущности данных идеологий говорящий может актуализировать определенные социальные представления, в рамках которых заявления и действия того или иного политика могут быть расценены как опасные, вредные, неприемлемые. Так, называя действующего президента My Main Marxist, the Obammunist, Islamomarxist, the Afro-Leninist, a X. Клинтон Socialist Extremist, Socio-Economic Marxist, говорящий апеллирует к неоднократным высказываниям этих политиков о необходимости принятия государственных мер по усовершенствованию системы распределения доходов в стране (что также отразилось в прозвище Б. Обамы the Wealth Spreader «Распределитель богатства»). Подобная практика, по представлению американцев, как правило, характерна для социалистических и коммунистических стран. Случаи совместного употребления ярлыковинвектив, апеллирующих к различным, порой противоречащим друг другу идеологическим понятиям, еще более наглядно демонстрируют факт утраты (в определенной степени) этими словами своего денотативного значения: Obama is the Demonic Anti-American Socialist Marxist Anti-Business Anti-Progress Islamist Anti-Semitic Racist Pig Destroying Our Economy (IX).

Оценочно нейтральное слово может также приобретать выраженные отрицательные коннотации благодаря метонимическому переносу. Так, в выступлениях британских политиков, посвященных сирийскому военному конфликту, фамилия сирийского президента Башара аль-Ассада (Bashar al-Assad) в не- 
которых случаях заменяет выражение the Assad regime «режим Ассада». В основе данной замены лежит связь значений по смежности, то есть метонимия. Антропоним Assad утрачивает свою родовую принадлежность и становится референтом понятия «режим Ассада», вызывая у реципиента ассоциации с диктатурой и беззаконием. Так, в речи министра иностранных дел Ф. Хэммонда имя собственное Assad применяется для обозначения жестокого и преступного режима, создавшего условия для деятельности экстремистских групп, поддерживающего с ними торговые и военные отношения и поэтому не менее опасного для Сирии, чем террористическая организация ИГИЛ (Исламское государство Ирака и Леванта, запрещенное в РФ): The Assad regime created the environment in which extremism and ISIL in particular flourished. So we reject the advice of those who say the poison of Assad is the cure of the cancer of ISIL. It is Assad who released jihadis in the early stages of the conflict. It is Assad who continues to trade with them even now (XIV). Метонимический перенос наблюдается и в высказывании британского посла в $\mathrm{OOH}$ М. Гранта, который утверждал, что в течение двух лет режим Ассада подвергает осаде сирийских граждан, лишая их доступа к гуманитарной помощи, а в настоящее время почти полмиллиона сирийцев - жителей района Дамаска, населенного преимущественно палестинцами, живут в условиях осады со стороны Ассада и ИГИЛ: Thousands of civilians, many children included, have been living under siege from the Assad regime for nearly two years and are trapped with little access to humanitarian assistance. The plight of the people in Yarmouk is the tragic reality for more than 440,000 Syrians currently under-siege by Assad and ISIL (XVI). В другом своем высказывании М. Грант заявляет о том, что «Ассад подавлял, калечил и убивал свой собственный народ»: For the past four years, Assad has repressed, maimed and killed his own people (XVI). Премьер-министр Великобритании Д. Кэмерон заявляет, что причиной массового исхода сирийцев из страны является терpop, устроенный Ассадом и ИГИЛ: The majority of these are Syrian refugees - fleeing the terror of Assad and ISIL which has seen more than 11 million people driven from their homes (XIII). В этом примере, как и в предыдущих, имя собственное Assad является субститутом понятия «режим Ассада», поскольку агентом всех этих действий может быть только противоправная, антигуманистическая политическая система.

\section{4}

Проведенное исследование позволило установить, что в американской политической риторике понятие «демократия» и выражающее его существительное democracy приобретают аксиологическую направленность: они соотносятся с такими значимыми общественными ценностями, как «мир» и «процветание». Демократия противопоставляется глобальным угрозам современного общества - экстремизму и радикализму. Отсубстантивное относительное прилагательное democratic развивает качественное значение и используется для выражения положительного оценочного признака. В то же время лексемы, эксплицирующие комплексные понятия «фашизм», «нацизм», «социализм», «коммунизм» и «марксизм», апеллирующие к чуждым для американского менталитета идеологиям, актуализируют для представителей данной лингвокультуры антиценности, что обусловливает их активное использование с целью создания ярлыков, имеющих выраженный инвективный характер. В британском политическом дискурсе топонимическое понятие «европейский», выраженное соответствующим прилагательным (European), трансформируется в культурно и идеологически значимый аксиологический концепт, который дискурсивно соотносится с такими общепризнанными ценностями, как свобода, равенство, демократия, правопорядок, безопасность и процветание. В рамках стратегии дискредитации политических лидеров антропонимы (например Assad) приобретают отрицательные оценочные коннотации, поскольку вследствие метонимического переноса становятся референтом понятия «Т Те Assad regime» («режим Ассада»), которое актуализирует незаконность и недемократичность руководства.

Описанные случаи дискурсивно детерминированного перехода оценочно нейтраль- 
ных лексических единиц в разряд лексики с выраженной коннотативной составляющей являются примером «натурализации» (термин Н. Фэрклаф) значений слов посредством доминирующей идеологии и культуры. Будучи системно-организованным набором утверждений, задающих параметры интерпретации явлений и событий, политический дискурс формирует отношение к предмету сообщения, а также создает и воспроизводит социальные представления.

\section{СПИСОК ЛИТЕРАТУРЫ}

Карасик, В. И. Языковая кристаллизация смысла / В. И. Карасик. - Волгоград : Парадигма, 2010. $-421 \mathrm{c}$.

Марьянчик, В. А. Аксиологичность политического текста / В. А. Марьянчик // Прагматика и семантика слова и текста : сб. ст. - Архангельск : Помор. ун-т, 2006. - С. 135-139.

Allott, N. The Role of Misused Concepts in Manufacturing Consent: A Cognitive Account / N. Allott // Manipulation and Ideologies in the Twentieth Century: Discourse, Language, Mind / ed. by L. de Saussure, P. Schulz. - Amsterdam ; Philadelphia : John Benjamins, 2005. - P. 147-168.

Dijk, T. A. van. Ideology: A Multidisciplinary Approach / T. A. van Dijk. - London : Sage, 1998. - 384 p.

Fairclough, N. Analyzing discourse: textual analysis for social research / N. Fairclough. - London : Routledge, 2003. - $270 \mathrm{p}$.

Fairclough, N. Language and Power / N. Fairclough. - London : Longman, 2001. - 226 p.

Habermas, J. Erkenntnis und Interesse / J. Habermas. - Frankfurt am Main : Suhrkamp, 1968. $235 \mathrm{p}$.

Pecheux, M. Language, semantics and ideology / M. Pecheux. - London : Macmillan, 1982. - 285 p.

Weiss, G. Critical Discourse Analysis Theory and Interdisciplinary / G. Weiss, W. Wodak. - New York : Palgrave Macmillan, 2002. - 335 p.

West, C. Doing gender / C. West, D. Zimmerman // Gender and Society. - 1987. - № 1. - P. 125-151.

\section{ИСТОЧНИКИ И СЛОВАРИ}

I- http://editorials.voa.gov/a/in-burma-gearingup-for-crucial-election/3033602.html.

II - http://editorials.voa.gov/a/ukrainian-winsdemocracy-defender-award/3224330.html.

III - http://editorials.voa.gov/content/defensedemocracy/3035349.html.
IV - http://editorials.voa.gov/content/dialoguenot-violence-needed-in-congo/3020647.html.

$V$ - http://editorials.voa.gov/content/kerry-inkyrgyzstan/3052029.html.

$V I-$ http://editorials.voa.gov/content/kerry-intunisia/3067408.html.

VII - http://editorials.voa.gov/content/ opportunity-for-peaceful-change-in-car/2992628.html.

VIII - http://editorials.voa.gov/content/ parliamentary-elections-in-azerbaijan/3052215.html.

$I X-\mathrm{https}$ ://maaadddog.wordpress.com/officialregistry-barack-obama-nicknames.

$X$ - https://www.gov.uk/government/speeches/ building-a-better-europe-making-the-eu-fit-for-thechallenges-ahead.

$X I$ - https://www.gov.uk/government/speeches/ eu-meeting-on-ukraine-david-camerons-speech.

$X I I$ - https://www.gov.uk/government/ speeches/minister-for-europe-sets-out-uk-approachto-eu-reform.

$X I I I$ - https://www.gov.uk/government/ speeches/syria-refugees-and-counter-terrorism-primeministers-statement.

$X I V$ - https://www.gov.uk/government/ speeches/the-assad-regime-created-the-environmentin-which-extremism-and-isil-in-particular-flourished.

$X V$-https:/www.gov.uk/government/speeches/ the-future-of-europe.

$X V I$ - https://www.gov.uk/government/ speeches/the-regional-turmoil-we-are-witnessingonly-reinforces-the-importance-of-resolving-theisrael-palestine-conflict.

XVII - http://www.hoaxofthecentury.com/ ClintonNaziSpyl.htm.

$O D$ - English Oxford Dictionaries. - Electronic text data. - Mode of access: http://www.oxford dictionaries.com/definition/english. - Title from screen.

PT-Power Thesaurus. - Electronic text data. Mode of access: https:/www.powerthesaurus.org/ democracy/antonyms. - Title from screen.

\section{REFERENCES}

Karasik V.I. Yazykovaya kristallizatsiya smisla [The Linguistic Crystallization of Meaning]. Volgograd, Paradigma Publ., 2010. 421 p.

Maryanchik V.A. Aksiologichnost politicheskogo teksta [The Axiological Aspect of a Political Text]. Pragmatika i semantika slova $i$ teksta: sb. st. [Pragmatics and Semantics of a Word and a Text. Collected Articles]. Arkhangelsk, Pomorskiy universitet Publ., 2006, pp. 135-139.

Allott N. The Role of Misused Concepts in Manufacturing Consent: A Cognitive Account. 
Saussure L. de, Schulz P., eds. Manipulation and Ideologies in the Twentieth Century: Discourse, Language, Mind. Amsterdam, Philadelphia, John Benjamins, 2005, pp. 147-168.

Dijk T.A. Van. Ideology: A Multidisciplinary Approach. London, Sage, 1998. 384 p.

Fairclough N. Analyzing discourse: textual analysis for social research. London, Routledge, 2003.270 p.

Fairclough N. Language and Power. London, Longman, 2001. 226 p.

Habermas J. Erkenntnis und Interesse [Knowledge and Interest]. Frankfurt am Main, Suhrkamp, 1968.235 p.

Pecheux M. Language, semantics and ideology. London, Macmillan, 1982. 285 p.

Weiss G., Wodak W. Critical Discourse Analysis Theory and Interdisciplinary. New York, Palgrave Macmillan, 2002. 335 p.

West C., Zimmerman D. Doing gender. Gender and Society, 1987, no. 1, pp. 125-151.

\section{SOURCES AND DICTIONARIES}

http://editorials.voa.gov/a/in-burma-gearingup-for-crucial-election/3033602.html.

http://editorials.voa.gov/a/ukrainian-winsdemocracy-defender-award/3224330.html.

http://editorials.voa.gov/content/defensedemocracy/3035349.html.

http://editorials.voa.gov/content/dialogue-notviolence-needed-in-congo/3020647.html.

http://editorials.voa.gov/content/kerry-inkyrgyzstan/3052029.html. http://editorials.voa.gov/content/kerry-intunisia/3067408.html.

http://editorials.voa.gov/content/opportunityfor-peaceful-change-in-car/2992628.html.

http://editorials.voa.gov/content/parliamentaryelections-in-azerbaijan/3052215.html.

https://maaadddog.wordpress.com/officialregistry-barack-obama-nicknames.

https://www.gov.uk/government/speeches/ building-a-better-europe-making-the-eu-fit-for-thechallenges-ahead.

https:/www.gov.uk/government/speeches/eumeeting-on-ukraine-david-camerons-speech.

https://www.gov.uk/government/speeches/ minister-for-europe-sets-out-uk-approach-to-eureform.

https://www.gov.uk/government/speeches/ syria-refugees-and-counter-terrorism-prime-ministersstatement.

https:/www.gov.uk/government/speeches/theassad-regime-created-the-en vironment-in-whichextremism-and-isil-in-particular-flourished.

https:/www.gov.uk/government/speeches/thefuture-of-europe.

https:/www.gov.uk/government/speeches/theregional-turmoil-we-are-witnessing-only-reinforcesthe-importance-of-resolving-the-israel-palestineconflict.

http://www.hoaxofthecentury.com/ClintonNaziSpyl. htm.

English Oxford Dictionaries. http://www. oxforddictionaries.com/definition/english.

Power Thesaurus. https://www.powerthesaurus. org/democracy/antonyms.

\section{Information About the Author}

Tatyana M. Golubeva, Candidate of Sciences (Philology), Associate Professor, Department of Professional Foreign-Language Communication, Kozma Minin Nizhny Novgorod State Pedagogical University (Minin University), Ulyanova St., 1, 603950 Nizhniy Novgorod, Russian Federation, gtm77@mail.ru, http://orcid.org/0000-0002-3909-5364.

\section{Информация об авторе}

Татьяна Михайловна Голубева, кандидат филологических наук, доцент кафедры иноязычной профессиональной коммуникации, Нижегородский государственный педагогический университет имени К. Минина (Мининский университет), ул. Ульянова, 1, 603950 г. Нижний Новгород, Российская Федерация, gtm77@mail.ru, http://orcid.org/0000-0002-3909-5364. 